\title{
Efforts to Improve PBI/Acid Membrane System for High Temperature Polymer Electrolyte Membrane Fuel Cell (HT-PEMFC)
}

\author{
Nur Anati Bazilah Daud ${ }^{1,2}$ Ebrahim Abouzari Lotf ${ }^{1,3 *}$ Saidatul Sophia Sha'rani ${ }^{1,2}$ \\ Mohamed M. Nasef ${ }^{1,4}$ Arshad Ahmad ${ }^{1,3}$, Roshafima Rasit Ali $^{2}$ \\ ${ }^{1}$ Center of Hydrogen Energy, Institute of Future Energy, Universiti Teknologi Malaysia, Malaysia. \\ ${ }^{2}$ Malaysia-Japan International Campus, Universiti Teknologi Malaysia, Malaysia. \\ ${ }^{3}$ Department of Chemical Engineering, Universiti Teknologi Malaysia, Johor Bahru, Malaysia. \\ ${ }^{4}$ Chemical Engineering Department, Universiti Teknologi Petronas,Perak, Malaysia
}

\begin{abstract}
The global expansion of industry and technology has brought various environmental issues especially in atmospheric pollution and global warming. These resulted in various R\&D activities on renewable energy resources and devices. Developing high temperature polymer electrolyte membrane fuel cell (HT-PEMFC) is one of them. Over the past decades, this research has been received the most attention for various stationary and transportation applications. This is due to inherent advantages of operation above $100^{\circ} \mathrm{C}$ including improved tolerance toward $\mathrm{CO}$ poisoning, enhanced electrode kinetics, easier heat dissipation and water management as well as better thermodynamic quality of the produced heat. Poly (benzimidazoles)phosphoric acid (PBI/PA) is the well-established membrane for HT-PEMFC applications replacing perfluorinated sulfonic acid (PFSA) membranes, which operate in the temperature range of below $100^{\circ} \mathrm{C}$. Nevertheless, there have been concerns on the durability and stability of such PEMFC, which negatively affected their widespread commercialization. In this paper, problems regarding this acid-base complex membrane system and modifications as well as some techniques used to overcome these issues will be outlined.
\end{abstract}

Keywords: Renewable energy resources and devices, stationary and transportation application, HT-PEMFC, PBI/PA, acid-base complex membrane system,

\section{INTRODUCTION}

A fuel cell is an electrochemical device that can converts chemical energy from fuel into electrical energy via electrochemical oxidation of the fuel at anode and reduction of oxidant at cathode (Fig. 1). Fuel cell possesses several advantages over other energy devices including broad fuel choices, generate continuous electricity as long as the reactants are being replenished, high-energy conversion efficiency which is up to $80 \%$, and environmentally friendly as no pollutant emission happens since water is the only chemical by-product [1].

\footnotetext{
* Corresponding author: ebrahim@utm.my
} 
There are many types of fuel cell that have been developed at the industrial level. Among all, polymer electrolyte membrane fuel cell (PEMFC) has gained the most attention especially for automotive and small stationary applications due to its comparatively high power density, low operation temperature, and fast start-up capability [2].

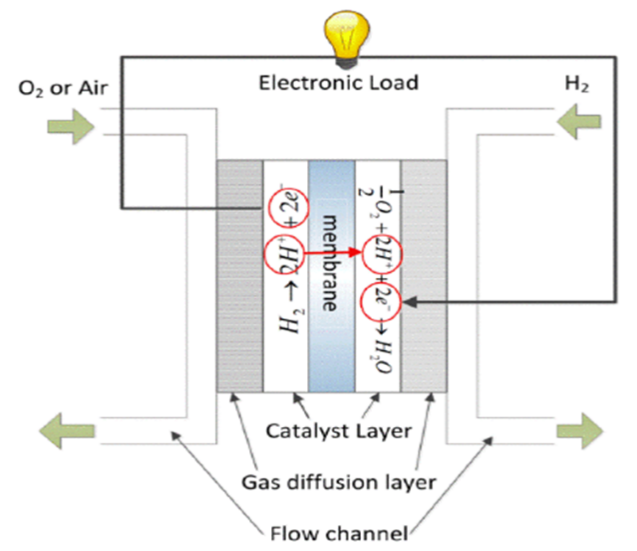

Fig.1 : The structure and operational principle of PEM fuel cell (Zhou, 2018).

In a fuel cell system, polymer electrolyte membrane (PEM) is the core component. Therefore, extensive studies has been done in order to establish PEM with high proton conductivity, low electronic conductivity and permeability to fuel, low electroosmotic drag coefficient, good thermal and chemical stability, good mechanical properties and low cost [3]. Traditionally, perfluorinated sulfonic acid (PFSA) membranes have been widely used for PEMFC due to the excellent stability and high conductivity in the temperature range below $100^{\circ} \mathrm{C}$. However, this type of membrane only offers a low temperature PEMFC (LT-PEMFC) system which has two main limitations mainly in their high cost and operational condition that required the system to be fully hydrated to maintain a high proton conductivity [4].

These drawbacks urge more research on other types of PEM for high temperature PEMFC (HT-PEMFC) which operate in a range of 100 to $200{ }^{\circ} \mathrm{C}$. HT-PEMFC operated at $>100{ }^{\circ} \mathrm{C}$ are considered as the next generation of fuel cell technology. This is due to the cost reduction and reliability in eliminating several issues faced by LT-PEMFC especially in terms of improved heat rejection, water management, reaction kinetics, and catalyst tolerance [5]. Most research on HT-PEMFC employed Poly (benzimidazoles) (PBI) that is lower in cost compared to PFSA and exhibits thermally and chemically stable properties under various conditions. Studies show that acid-base complex membrane system mainly acid-doped PBI membranes showed very good properties that allow them to be used in PEMFC at the temperature up to $200{ }^{\circ} \mathrm{C}$ without humidification [6]. Several types of acid that is possible to be doped with PBI membrane are $\mathrm{HCl}, \mathrm{HNO}_{3}, \mathrm{H}_{2} \mathrm{SO}_{4}$ and $\mathrm{HClO}_{4}$. However, the most preferable acid dopant is by using phosphoric acid $\left(\mathrm{H}_{3} \mathrm{PO}_{4}\right)$ since this type of acid dopant exhibit an outstanding thermal stability, high proton conductivity and very low vapour pressure at elevated temperature [7].

\section{CHALLENGES ON PBI/ACID MEMBRANE SYSTEM}

There are several limitations for HT-PEMFC, which limit their further industrial scaleup, including (i) degradation of membrane during electrochemical process, (ii) low acid doping level and low conductivity at dry conditions, (iii) acid leaching from the acid doped membrane, and (iv) poisoning of catalyst by phosphoric acid (PA). 
Firstly, degradation of membrane happened in the presence of redox species. The mode of degradation for the PA doped membranes includes chemical oxidative degradation, thermal stress degradation, and mechanical degradation. Generally, chemical degradation happened due to the attack of $\mathrm{C}-\mathrm{H}$ bond in the polymer by hydrogen peroxide $\left(\mathrm{H}_{2} \mathrm{O}_{2}\right)$ and its radical $(\dot{\mathrm{OH}}$ or $\mathrm{OOH})$ which generated by oxygen reduction reaction in the cathode and by reaction of hydrogen and oxygen in the anode [8]. In addition, when the temperature exceeds $100^{\circ} \mathrm{C}$, dehydration will result in large ohmic losses, low operating cell voltages and low power densities [7]. Apart from that, the rate of materials degradation and mechanical failure also increases as the temperature increases.

Next, the conductivity of PBI/PA membrane greatly depends on the level of acid doping, where PBI/PA membranes exhibit high conductivity only with high acid loadings, at least higher than 3.0 PA molecules per repeat unit of PBI. However, excess PA content would affect the mechanical stability of the membrane and leaching problems of electrolytes due to the plasticizing effect of the PA doping, especially at higher temperature [9]. These situations may result in a reduction of conductivity due to the free acid which can be lost along with evaporated water. To overcome the problem, the doping level of acid should be reduced and this would negatively affect the conductivity of the PBI/PA membrane.

Even though aforementioned limitations have been improved by some technical advancement, acid leaching from PBI/PA materials is still a serious concern that leads to serious degradation of fuel cell components, which in turn affect the power density, and the performance of the fuel cell, especially for long-term operation. Based on the results obtained by Leykin, et al. (2010), during the first $10 \mathrm{~min}$, the major part of acid leaves the membrane since they are not chemically bound to the polymer but retained in the polymer via relatively weak hydrogen bonding and dipole interaction [10]. As a result, a fast extraction of overstoichiometric amounts of acid is happened. This problem will consequently cause inhomogeneous PA distribution, which then decreases the proton conductivity and degenerate the PEMFC performance during long-term operation [11]. In addition, leaching of PA could also diminish the oxygen reduction reaction (ORR) activity of Pt-based cathode since $\mathrm{Pt}$ catalyst will be poisoned by chemisorbed dihydrogen phosphate $\left(\mathrm{H}_{2} \mathrm{PO}_{4}^{-}\right)$and hydrogen phosphate $\left(\mathrm{HPO}_{4}{ }^{2-}\right)$ ions [12]. According to $\mathrm{Su}$, et al. (2013), this sluggish kinetics of ORR and the transport limitations of protons and reactants in the cathode greatly limit the operation of PEMFC cell performance at high temperature [13].

\section{METHODS TO IMPROVE PBI/ACID MEMBRANE SYSTEM}

\subsection{IMPROVE ACID DOPING LEVEL AND REDUCE ACID LEACHING}

As stated in the previous section, the main issue that needs to be improved is the low acid doping level and PA leaching from PEM. To date, various type of PBI/PA membrane has been modified and fabricated successfully. Some of the modification are outlined as follow.

\subsubsection{The Introduction of Nitrogen Containing Group}

It is believed that increasing the molecular weight of PBI polymers and by exploring new methods of membrane preparation will improve the mechanical properties of PA-doped PBI with high proton conductivity and high PA doping level. Kallitsis group introduced the use of pyridine units as basic moieties in a rigid aromatic polymer in 2003. Pyridine group is an alkaline group that has an aromatic structure with a nitrogen with a lone pair electron. It can be used to elevate the phosphoric acid doping level of HT-PEMFC. In addition, the 
oxidative stability of the membranes can also be improved since this pyridine group can easily react with free radicals [14]. This method was widely used in the literature and resulted in significant enhancements in acid doping level of the membranes [15 - 18].

In another interesting study by Chen, et al. (2018), they synthesized a series of sulfonated PBI multiblock copolymers containing pyridine rings (Fig. 2) [14]. The presence of the pyridine group increases the acid-base interaction between the sulfonic acid group and the alkaline group, hence, improving the chemical stability of the membrane. It was proven that all the copolymer membrane showed good dimensional stability, mechanical properties, thermal stability and chemical stability. In addition, by increasing the basicity of copolymer, also helped to increase the phosphoric acid doping level which result an increase in proton conductivity after doping with $\mathrm{H}_{3} \mathrm{PO}_{4}$. Meanwhile, after doping with $\mathrm{H}_{3} \mathrm{PO}_{4}$, the proton conductivity of this copolymer membrane also showed an increasing value from $5.5 \times 10^{-2}$ to $2.3 \times 10^{-1} \mathrm{~S} \mathrm{~cm}^{-1}$ at $180^{\circ} \mathrm{C}$ and $100 \%$ relative humidity. The increment in the proton conductivity was due to increasing of phosphoric acid doping level of copolymer membrane. With the increasing of PA doping level, the spaces among the molecules chains become larger, providing easier transport channels for $\mathrm{H}_{4} \mathrm{PO}_{4}{ }^{+}$.

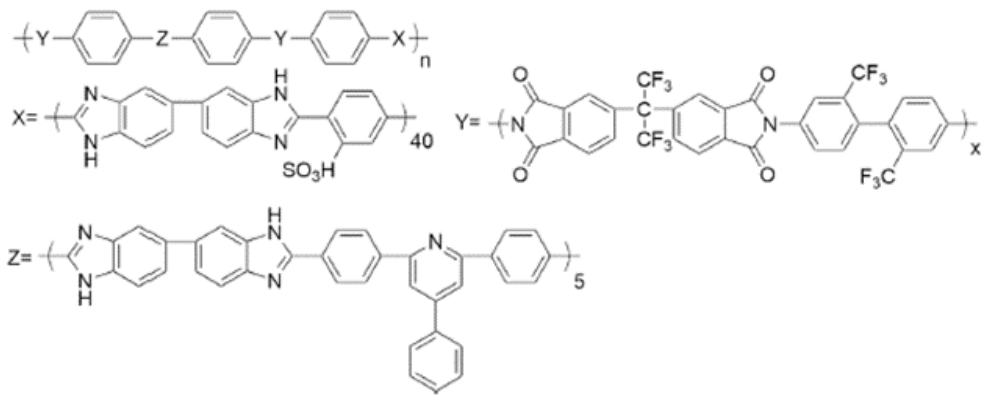

Fig.2 : Sulfonated PBI multiblock copolymers containing pyridine rings (Chen et al., 2018).

\subsubsection{The Introduction of Inorganic Filler}

Introducing various inorganic filler as an additive greatly contributes to the improvement of the membrane structure and its intrinsic ability to conduct protons. Research found that the addition of a composite or a nanocomposite membrane to PBI would make some improvements on proton conductivity, water/PA uptake and retention, durability, mechanical and thermal properties as well as fuel cell performance [19].

As a first generation, fillers such as silica [20], titanium [21], zirconia [15, 16], and carbon materials $[22,23]$ have been introduced and some improvement in terms of dimensional stability, mechanical properties and gas permeability of PBI composite membrane have been reported. Recently, great attention has been moved toward a second generation which containing acid functionalized fillers such as various carbon-based substrates including graphite [9], graphene oxide (GO) [23] and carbon nanotubes (CNT) [24] and silica [25] functionalized with carboxylic acid [26], sulfonic acid and protic ionic [25] liquids in addition to solid and heteropolyacid. In addition, the acid functionality of inorganic fillers, provides better fillers dispersions and improves polymer-filler compatibility which directly affects the gas permeability, dimensional stability and mechanical integrity of membranes.

In a study conducted by Yang, et al. (2015), they managed to improve both proton conductivity and mechanical properties by introducing a PBI composite membrane with welldispersed triazole-modified GO (Fig. 3) [22]. This modified GO by triazole showed an excellent distribution in Dimethylacetamide (DMAc) and possessed improved compatibility 
with PBI polymer. In addition, the high proton conductivity of $0.135 \mathrm{~S} \mathrm{~cm}^{-1}$ at $180{ }^{\circ} \mathrm{C}$ was achieved by the PA doped PBI/MGO membrane since the triazole groups in MGO was successfully interacted with doped acid PA. Therefore, a network of hydrogen bonds is formed and the proton conduction is improved.

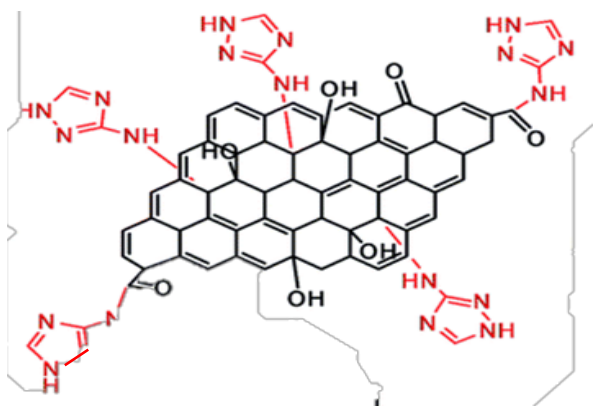

Fig.3 : Triazole modified graphene oxide (Yang et al., 2015).

In a recently conducted study, researchers managed to fabricate a new class of highly conductive and durable composite membrane for HT-PEMFC application under anhydrous condition [31]. In this study, they introduced a highly phosphonated graphene oxide (PGO) to 2, 6-Pyridine functionalized Polybenzimidazole (Py-PBI) substrate. Different acid doping level and conductivity, durability and fuel cell performance of developed membrane were evaluated. As shown in Fig. 4, phosphonated GO was successfully prepared from graphite in a three-step procedure [32-33]. According to the stabilised methods, $\mathrm{PGO}$ with $\mathrm{P} / \mathrm{C}$ elemental ratio of 0.13 was prepared when reacting with a homogenized mixture of polyphosphoric acid and PA leading toward the successful of oxidation and exfoliation of phosphonated GO.

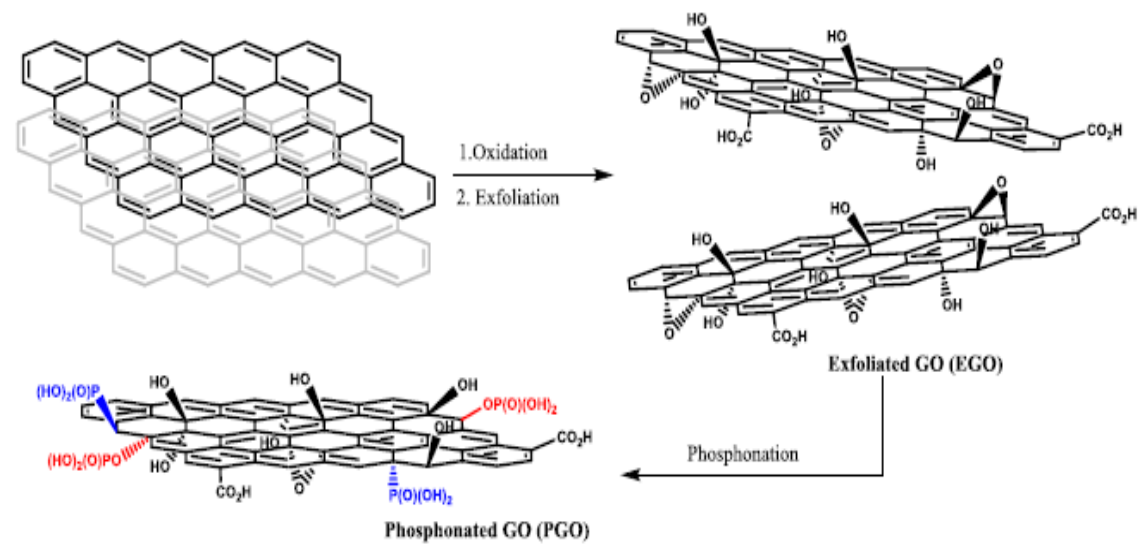

Fig.4: Schematic route of functionalization of graphene oxide (Abouzari et al., 2018).

From the obtained result, high proton conductivity of $76.4 \times 10^{-3} \mathrm{~S} \mathrm{~cm}^{-1}$ was achieved at $140{ }^{\circ} \mathrm{C}$ under the anhydrous condition and the conductivity was more stable with the presence of PGO (Fig.5). In addition, this developed composite membrane also showed above $75 \%$ improvement with a peak power density of $>359 \mathrm{mWcm}^{-2}$ at $120{ }^{\circ} \mathrm{C}$ under the anhydrous condition compared to the membrane without the phosphonated filler (Fig.6). This research proved that the stability of the acid content greatly affected by the content of PGO since this filler inherent excellent mechanical properties, large specific surface area and high proton conductivity of $10^{-2} \mathrm{~S} \mathrm{~cm}^{-1}$ [34]. 

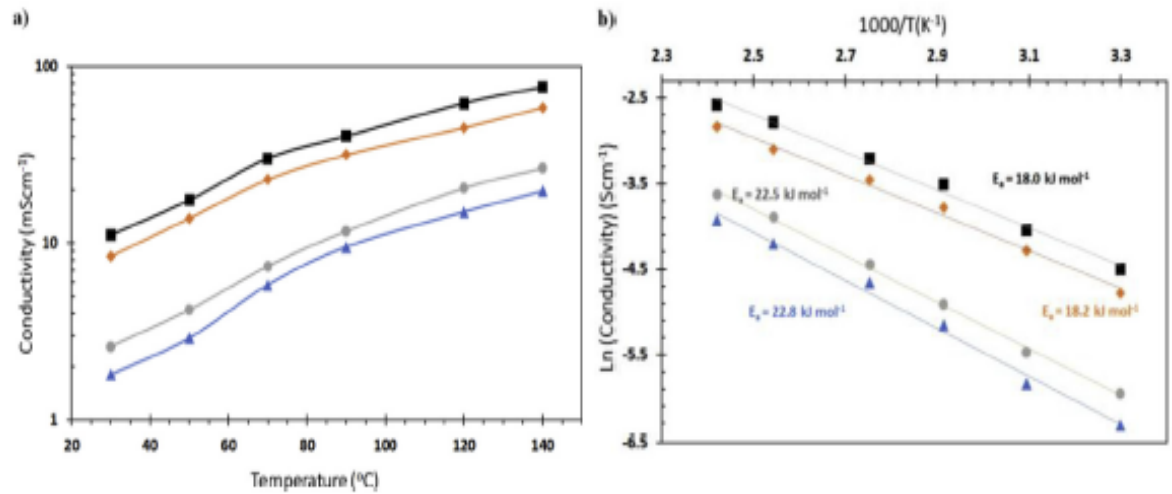

Fig.5 : Variation of the proton conductivity of the developed membranes with the temperature (a) and Arrhenius plot of conductivity under dry conditions ( $\triangle$ : py-PBI/PA, $\bullet$ : py-PBI/0.5\% PGO/PA, :py- PBI/1.0\% PGO/PA, n: py-PBI/1.5\% PGO/PA) (Abouzari et al., 2018).

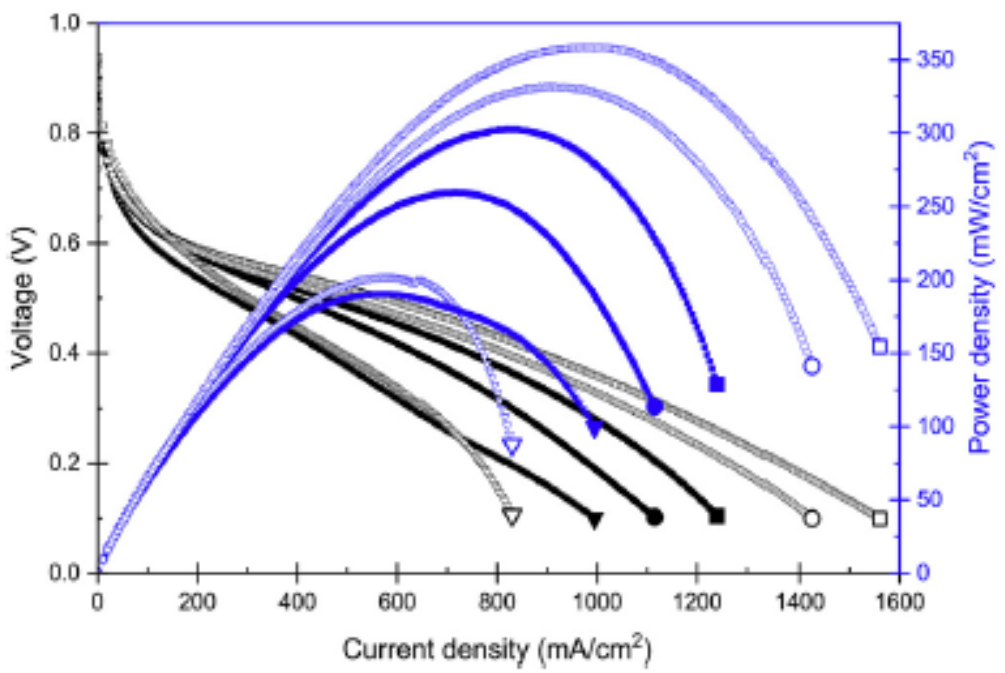

Fig.6 : Performance curves of various membranes with ADLs; Py-PBI ( $\boldsymbol{\nabla})$ andcomposite membranes with $1.0 \%(\bullet)$ and $1.5 \%(\bullet)$ of PGO in compared with corresponding as-doped membranes of Py-PBI

$(\Delta)$ and composite membranes with $1.0 \%(\circ)$ and $1.5 \%$ ( $\square$ ) of PGO (Abouzari et al., 2018).

\subsubsection{PBI Sol-Gel Membranes}

As stated in the previous section, at the high PA-doping level, PBI/PA membrane suffered from inferior mechanical properties. Recent studies showed that PBI/PA membrane could retain a high level of phosphoric acid in the gel structure and high ionic conductivities as well as stable mechanical properties even at a higher temperature.

This sol-gel process makes use of polyphosphoric acid (PPA) which is an efficient condensation reagent for the synthesis of high molecular weight PBI polymers in good yields. This extremely hygroscopic PPA will hydrolyse to PA upon absorption of moisture and may serve as a solvent for the direct casting of polymerization solution without isolation or redissolution of PBI polymer [27]. According to Chen, et al., the PBI membrane made by PPA sol-gel process can achieve an acid doping levels greater than 30 compared to the conventionally imbibed PBI membrane with only 5-6 molar ratio of PA to PBI repeat unit 
[26]. This group also successfully prepared a low-solids and highly acid-doped PBI membrane with outstanding fuel cell performance under anhydrous, ambient pressure, and high temperature $\left(120-200^{\circ} \mathrm{C}\right)$ operating condition. However, their long-term mechanical durability is the main concern since this type of PBI membrane is vulnerable under compressive loads at elevated temperature.

\subsection{ELECTROLYTE ADDITIVES AS POTENTIAL METHOD TO REDUCE PHOSPHATE ADSORPTION}

Phosphate adsorption on the surface of a platinum catalyst has become one of the main concerns for PBI/PA membrane. This urged more research on how to effectively block the phosphate adsorption and weakening the adsorbing behaviour of phosphate anion on platinum. Some of the works that have been done are outlined as follow.

Introducing additives to electrolyte may result in both higher solubility and higher diffusivity of the electrolyte. In addition, these additives may also help in reduction of phosphate adsorption. In literature, perfluorosulfonimide, 1-methyl imidazole, and trifluoromethane sulfonic acid have been used as an additive to the phosphoric acid electrolyte. Among all, the most promising candidates are additives based on fluorinated derivatives of phosphoric acid, since they are much more capable to weaken the adsorption of phosphate ion on the Pt catalyst surface [28].

In a recent study, two perfluoroalkyl phosphonic acid; $\mathrm{C}_{2} \mathrm{~F}_{5} \mathrm{PO}_{3} \mathrm{H}_{2}$ (pentafluoroethyl phosphonic acid, PFEPA) and $\mathrm{CF}_{3} \mathrm{PO}_{3} \mathrm{H}_{2}$ (trifluoromethyl phosphonic acid, TFMPA) have been investigated to improve the oxygen reduction reaction (ORR) of HT-PEMFC [28]. Based on the results, they successfully improved the ORR kinetics, and the PBI/PA membranes exhibited excellent thermal stability and the fuel cell's output power also increased consistently $\left(270 \mathrm{mWcm}^{-2}\right.$ vs. $\left.180 \mathrm{mWcm}^{-2}\right)$. There are three possible factors attributed to the improved ORR kinetics with both PFEPA and TFMPA additives. First, the improved wetting behaviour of acids extends the triple phase boundaries within the cathode [29]. Second, minimized phosphate anion adsorption on the catalyst particles prevented the blocking of the Pt active site [28]. Lastly, increased of $\mathrm{O}_{2}$ solubility in the acid mixture lowered the gas-transfer losses [30].

\section{CONCLUSION}

In spite of the advantages of HT-PEMFC compared to LT-PEMFC, there are major obstacles, which intercept them from being commercialized. Though phosphoric acid is considered as a successful acid dopant, there are also some drawbacks especially regarding on issue of phosphoric acid plaguing on the catalyst which causes further damage on the $\mathrm{Pt}$ catalyst. Apart from that, the issue on the degradation of the membrane during the electrochemical process due to the acid leaching from acid doped membrane also become one of a major drawback since it greatly affects the conductivity of membrane and also the performance of fuel cell. In this review, some modification of this acid-base complex membrane system as regards to overcoming the aforementioned problems, including the fabrication of PBI composite membrane by introducing nitrogen-containing group and an inorganic filler as well as fabrication of PBI sol-gel membrane were explained and proved to be successful. As a regard to the adsorption of phosphoric acid on Pt catalyst, apart from adding additives in electrolytes, using alternative acids as a dopant is recommend in the future as a way to achieve the highest overall performance. 


\section{ACKNOWLEDGEMENT}

This project is fully supported by Universiti Teknologi Malaysia and Ministry of Higher Education under Fundamental Grants (vote no. \#4F878) and MTJA \#4C116.

\section{REFERENCES}

1. H. Chen, T.N. Cong, W. Yang, C. Tan, Y. Li, Y. Ding, Progress In Electrical Energy Storage System: A Critical Review. Progress in Natural Science, 19(3), 291-312, (2009).

2. C. Song, R. Hui, J. Zhang, High-temperature PEM Fuel Cell Catalysts and Catalyst Layers. PEM Fuel Cell Electrocatalysis and Catalyst Layers, 2, 861-888, (2008).

3. S. Peighambardoust, S. Rowshanzamir, M. Amjadi, Review Of The Proton Exchange Membranes For Fuel Cell Applications. International Journal Of Hydrogen Energy, 35(17), 9349-9384, (2010).

4. J. Asensio, E. Sanchez, P. Gomez-Romero, ChemInform Abstract: Proton-Conducting Membranes Based On Benzimidazole Polymers For High-Temperature PEM Fuel Cells. $A$ Chemical Quest. Cheminform, 39, 3210-3239, (2010).

5. R. Rosli, A. Sulong, W. Daud, M. Zulkifley, T. Husaini, M. Rosli, A Review Of HighTemperature Proton Exchange Membrane Fuel Cell (HT-PEMFC) System. International Journal of Hydrogen Energy, 42(14), 9293-9314, (2017).

6. Q. Li, R. He, J. Jensen, N. Bjerrum, PBI-Based Polymer Membranes for High Temperature Fuel Cells- Preparation, Characterization and Fuel Cell Demonstration. Fuel Cells, 4(3), 147-159, (2004).

7. S. Bose, T. Kuila, T. Nguyen, N. Kim, K. Lau, J. Lee, Polymer Membranes For High Temperature Proton Exchange Membrane Fuel Cell: Recent Advances And Challenges. Progress in Polymer Science, 36(6), 813-843, (2011).

8. F. Zhou, Degradation Of H3PO4/PBI High Temperature Polymer Electrolyte Membrane Fuel Cell Under Stressed Operating Conditions : Effect of Start/Stop Cycling, Impurities Poisoning and H2 Starvation. Department of Energy Technology, Aalborg University (Doctoral dissertation), (2015).

9. C. Xu, Y. Cao, R. Kumar, X. Wu, X. Wang, K. Scott, A Polybenzimidazole/Sulfonated Graphite Oxide Composite Membrane For High Temperature Polymer Electrolyte Membrane Fuel Cells. Journal Of Materials Chemistry, 21(30), 11359, (2011).

10. A. Leykin, A. Askadskii, V. Vasilev, A. Rusanov, Dependence Of Some Properties Of Phosphoric Acid Doped Pbis On Their Chemical Structure. Journal of Membrane Science, 347(1-2), 69-74, (2010).

11. M. Berber, T. Fujigaya, K. Sasaki, N. Nakashima, Remarkably Durable High Temperature Polymer Electrolyte Fuel Cell Based on Poly (vinylphosphonic acid)-doped Polybenzimidazole. Scientific Reports, 3(1), 1764, (2013).

12. X. Li, Structure-Property Relationships In Polybenzimidazole Materials For Gas Separation And Fuel Cell Applications. (Doctoral dissertation), (2014).

13. H. Su, S. Pasupathi, B. Bladergroen, V. Linkov, B.G. Pollet, Performance Investigation Of Membrane Electrode Assemblies For High Temperature Proton Exchange Membrane Fuel Cell. Journal of Power and Energy Engineering, 01(05), 95-100, (2013).

14. S. Chen, H. Pan, Z. Chang, M. Jin, H. Pu, Synthesis And Study Of Pyridine-Containing Sulfonated Polybenzimidazole Multiblock Copolymer For Proton Exchange Membrane Fuel Cells. Ionics, 1-11, (2018).

15. M.M. Nasef, T. Fujigaya, E. Abouzari-Lotf, N. Nakashima, Electrospinning Of Poly(Vinylpyrrodine) Template For Formation Of Zro2 Nanoclusters For Enhancing 
Properties Of Composite Proton Conducting Membranes. International Journal of Polymeric Materials and Polymeric Biomaterials, 66 (6), 289-298, (2017).

16. M.M. Nasef, T. Fujigaya, E. Abouzari-Lotf, N. Nakashima, Z. Yang, Enhancement Of Performance Of Pyridine Modified Polybenzimidazole Fuel Cell Membranes Using Zirconium Oxide Nanoclusters And Optimized Phosphoric Acid Doping Level. International Journal of Hydrogen Energy, 41 (16), 6842-6854, (2016).

17. L. Xiao, H. Zhang, T. Jana, E. Scanlon, R. Chen, E. Choe, Synthesis And Characterization Of Pyridine-Based Polybenzimidazoles For High Temperature Polymer Electrolyte Membrane Fuel Cell Applications. Fuel Cells, 5(2), 287-295, (2005).

18. J. Yang, Y. Xu, L. Zhou, Q. Che, R. He, Q. Li, Hydroxyl Pyridine Containing Polybenzimidazole Membranes For Proton Exchange Membrane Fuel Cells. Journal of Membrane Science, 446, 318-325, (2013).

19. E. Quartarone, S. Angioni, P. Mustarelli, Polymer and Composite Membranes for ProtonConducting, High-Temperature Fuel Cells: A Critical Review. Materials, 10(12), 687, (2017).

20. F. Liu, S. Wang, J. Li, X. Tian, X. Wang, H. Chen, Z. Wang, Polybenzimidazole/IonicLiquid-Functional Silica Composite Membranes With Improved Proton Conductivity For High Temperature Proton Exchange Membrane Fuel Cells. Journal of Membrane Science, 541, 492-499, (2017).

21. F.J. Pinar, P. Canizares, M.A. Rodrigo, D. Ubeda, J. Lobato, Titanium Composite PBIBased Membranes For High Temperature Polymer Electrolyte Membrane Fuel Cells. Effect On Titanium Dioxide Amount. RSC Advances, 2 (4), 1547-1556, (2012).

22. J. Yang, C. Liu, L. Gao, J. Wang, Y. Xu, R. He, Novel Composite Membranes Of Triazole Modified Graphene Oxide And Polybenzimidazole For High Temperature Polymer Electrolyte Membrane Fuel Cell Applications. RSC Advances, 5 (122), 101049101054, (2015).

23. K.J. Peng, J.Y. Lai, Y.L. Liu, Nanohybrids Of Graphene Oxide Chemically-Bonded With Nafion: Preparation And Application For Proton Exchange Membrane Fuel Cells. Journal of Membrane Science, 514, 86-94, (2016).

24. M.M. Hasani-Sadrabadi, E. Dashtimoghadam, F.S. Majedi, H. Moaddel, A. Bertsch, P. Renaud, Superacid-Doped Polybenzimidazole-Decorated Carbon Nanotubes: A Novel High-Performance Proton Exchange Nanocomposite Membrane. Nanoscale, 5 (23), 11710-11717, (2013).

25. S. Maity, S. Singha, T. Jana, Low Acid Leaching PEM For Fuel Cell Based On Polybenzimidazole Nanocomposites With Protic Ionic Liquid Modified Silica. Polymer, 66, 76-85, (2015).

26. X. Chen, G. Qian, M. Molleo, B. Benicewicz, H. Ploehn, High Temperature Creep Behavior Of Phosphoric Acid-Polybenzimidazole Gel Membranes. Journal Of Polymer Science Part B: Polymer Physics, 53(21), 1527-1538, (2015).

27. L. Xiao, H. Zhang, E. Scanlon, L. Ramanathan, E. Choe, D. Rogers, High-Temperature Polybenzimidazole Fuel Cell Membranes via a Sol-Gel Process. Chemistry Of Materials, 17(21), 5328-5333, (2005).

28. F. Mack, S. Galbiati, V. Gogel, L. Jörissen, R. Zeis, Evaluation of Electrolyte Additives for High-Temperature Polymer Electrolyte Fuel Cells. Chemelectrochem, 3(5), 770-773. (2016).

29. X. Gang, Electrolyte Additives for Phosphoric Acid Fuel Cells. Journal Of The Electrochemical Society, 140(4), 896, (1993).

30. M. Enayetullah, E. O'Sullivan, E. Yeager, Oxygen Reduction On Platinum In Mixtures Of Phosphoric And Trifluoromethane Sulphonic Acids. Journal Of Applied Electrochemistry, 18(5), 763-767, (1988). 
31. E. Abouzari-Lotf, M. Zakeri, M. Nasef, M. Miyake, P. Mozarmnia, N. Bazilah, N., Emelin, and A. Ahmad, Highly Durable Polybenzimidazole Composite Membranes with Phosphonated Graphene Oxide for High Temperature Polymer Electrolyte Membrane Fuel Cells. Journal of Power Sources, 412, 238-245, (2018).

32. M. Etesami, E. Abouzari-Lotf, A. Ripin, M. Mahmoud Nasef, T.M. Ting, A. Saharkhiz, A. Ahmad, Phosphonated Graphene Oxide with High Electrocatalytic Performance for Vanadium Redox Flow Battery. Int. J. Hydrogen Energy, 43 (1), 189-197, (2018)

33. M. Zakeri, E. Abouzari-lotf, M. Miyake, S. Mehdipour-Ataei, K. Shameli, Phosphoric Acid Functionalized Graphene Oxide: A Highly Dispersible Carbon-Based Nanocatalyst for The Green Synthesis of Bio-Active Pyrazoles, Arabian. J. Chem, (2017),

34. J. Dong, Z. Yao, T. Yang, L. Jiang, C. Shen, Control of Superhydrophilic and Superhydrophobic Graphene Interface, Sci. Rep. 3, 1733, (2013). 